\title{
Nanoparticles prepared from the water extract of Gusuibu (Drynaria fortunei J. Sm.) protects osteoblasts against insults and promotes cell maturation
}

\author{
This article was published in the following Dove Press journal: \\ International Journal of Nanomedicine \\ 5 July $201 \mathrm{I}$ \\ Number of times this article has been viewed
}

\author{
Chung-King Hsu',2 \\ Mei-Hsiu Liao ${ }^{3}$ \\ Yu-Tyng Tai ${ }^{4}$ \\ Shing-Hwa Liu ${ }^{5}$ \\ Keng-Liang $\mathrm{Ou}^{6}$ \\ Hsu-Wei Fang ${ }^{7}$ \\ I-Jung Lee ${ }^{8}$ \\ Ruei-Ming Chen ${ }^{2,3}$ \\ 'Institute of Materials Science and \\ Engineering, National Taipei University \\ of Technology, ${ }^{2}$ Cell Physiology and \\ Molecular Image Research Center, \\ Taipei Medical University-Wan \\ Fang Medical Center, ${ }^{3} \mathrm{Graduate}$ \\ Institute of Medical Sciences, Taipei \\ Medical University, ${ }^{4}$ Department \\ of Anesthesiology, Taipei Medical \\ University-Wan Fang Medical Center, \\ ${ }^{5}$ Institute of Toxicology, College of \\ Medicine, National Taiwan University, \\ ${ }^{6} \mathrm{Graduate}$ Institute of Biomedical \\ Materials and Engineering, Taipei \\ Medical University, ${ }^{7}$ Department \\ of Chemical Engineering and \\ Biotechnology, National Taipei \\ University of Technology, ${ }^{8}$ Division of \\ Information and Herbarium, National \\ Research Institute of Chinese \\ Medicine, Taipei, Taiwan
}

Correspondence: Ruei-Ming Chen Graduate Institute of Medical Sciences, College of Medicine, Taipei Medical University, 250 Wu-Xing St.,

Taipei I I0, Taiwan

Tel +88622736166I ext 3222

Fax +88628662III9

Email rmchen@tmu.edu.tw

\begin{abstract}
Our previous study showed that Gusuibu (Drynaria fortunei J. Sm.) can stimulate osteoblast maturation. This study was further designed to evaluate the effects of nanoparticles prepared from the water extract of Gusuibu (WEG) on osteoblast survival and maturation. Primary osteoblasts were exposed to $1,10,100$, and $1000 \mu \mathrm{g} / \mathrm{mL}$ nanoparticles of WEG (nWEG) for 24,48 , and 72 hours did not affect morphologies, viability, or apoptosis of osteoblasts. In comparison, treatment of osteoblasts with $1000 \mu \mathrm{g} / \mathrm{mL}$ WEG for 72 hours decreased cell viability and induced DNA fragmentation and cell apoptosis. nWEG had better antioxidant bioactivity in protecting osteoblasts from oxidative and nitrosative stress-induced apoptosis than WEG. In addition, nWEG stimulated greater osteoblast maturation than did WEG. Therefore, this study shows that WEG nanoparticles are safer to primary osteoblasts than are normal-sized products, and may promote better bone healing by protecting osteoblasts from apoptotic insults, and by promoting osteogenic maturation.
\end{abstract}

Keywords: Gusuibu, nanoparticles, cell protection, osteoblast maturation

\section{Introduction}

Nanomedicine has developed into a new scientific field. ${ }^{1,2}$ For example, changes in the resonance of a localized nanoparticle surface plasmon upon particle aggregation are constructive to optically detect biomolecular interactions. ${ }^{3,4}$ When Danshen (Salvia miltiorrhiza) was prepared as nanoparticles, the nanoproducts enhanced antioxidant bioactivity. ${ }^{5}$ In addition, nano-Ganoderma spores are more easily taken up and have better antitumor activity. ${ }^{6}$ Thus, nanoparticles prepared from traditional medicines possess new pharmacokinetic and pharmacodynamic characteristics and can be applied to develop new therapeutic strategies.

Bone fractures are a common accident. During the healing process of bone fractures, osteoblast differentiation and maturation sequentially occur and ultimately stimulate bone formation. ${ }^{7,8}$ Meanwhile, bone fracture-triggered inflammation can elevate oxidative or nitrosative stress and usually impairs bone healing. ${ }^{9}$ Our previous studies showed that oxidative and nitrosative stress can reduce alkaline phosphatase activity and induce apoptotic insults to rat calvarial osteoblasts through a mitochondrial-dependent pathway. ${ }^{10,11} \mathrm{~A}$ variety of biomolecules participate in regulating inflammation-induced osteoblast injury. ${ }^{12-14}$ Reducing such stress-caused damage can promote osteoblast maturation and bone healing. Our previous studies showed that Gusuibu, a traditional 
Chinese herb, can protect osteoblasts from oxidative stressinduced insults and promotes osteogenic differentiation. ${ }^{15,16}$

Drynaria fortunei J. Sm. (Pteridophyta) is a variety of the traditional Chinese herb Gusuibu, which is frequently applied to prevent or treat bone-related diseases. Wang et al reported that the components of Gusuibu exhibited proliferative activity in osteoblast-like UMR106 cells. ${ }^{17}$ In addition, the flavonoid fractions of Gusuibu can prevent nephrotoxicity and excite regeneration of primary kidney epithelial tubular cells. ${ }^{18}$ Our previous study showed that the water extract of Gusuibu can protect rat calvarial osteoblasts from hydrogen peroxide-induced insults. ${ }^{16}$ In an animal study, crude extracts from Gusuibu were also shown to have systemic effects on bone formation in mice. ${ }^{19}$ Recently, we provided supplementary evidence to show that the water extract of Gusuibu can promote osteoblast differentiation through regulating osteogenic differentiation-related gene expression. ${ }^{15}$ Nanomedicine is a growing scientific field which may be broadly applicable to develop novel strategies to prevent and treat bone diseases. Thus, the purposes of this study were to evaluate the effects of nanoparticles prepared from the water extract of Gusuibu on the cytotoxicity and cytoprotection against stress-induced insults to rat osteoblasts and the promotion of osteogenic maturation.

\section{Materials and methods}

\section{Preparation of the water extract of Gusuibu (WEG)}

Gusuibu (D. fortunei) was grown in Chengdu, Sichuan Province, China. The herb was provided by the Brion Research Institute, Sun Ten Group (Taipei, Taiwan), and identified by institutional experts according to macroscopic and microscopic approaches. In addition, the chemical and physical characteristics of $D$. fortunei are routinely analyzed, and the product was commercialized (CAS no. 6005, Sun Ten Pharmaceutical, Sun Ten Group). Dry pieces of $D$. fortunei (Figure 1A) were ground into a fine powder. WEG was prepared by decocting $50 \mathrm{~g}$ of herb powder with $400 \mathrm{~mL}$ water for 1 hour, as previously described. ${ }^{16}$ After filtration, the filtrate was frozen at $-70^{\circ} \mathrm{C}$ and then concentrated by a Freeze Dryer FD24 (Kingmech, Taiwan) into a dry powder. WEG was stored at room temperature and protected from light and moisture.

\section{Preparation of WEG nanoparticles}

Nanoparticles of WEG (nWEG) were prepared following a previously described method. ${ }^{20}$ Briefly, WEG was carefully ground up using an auto grinder-polisher $\left(\right.$ EcoMet $^{\circledR} 250$,
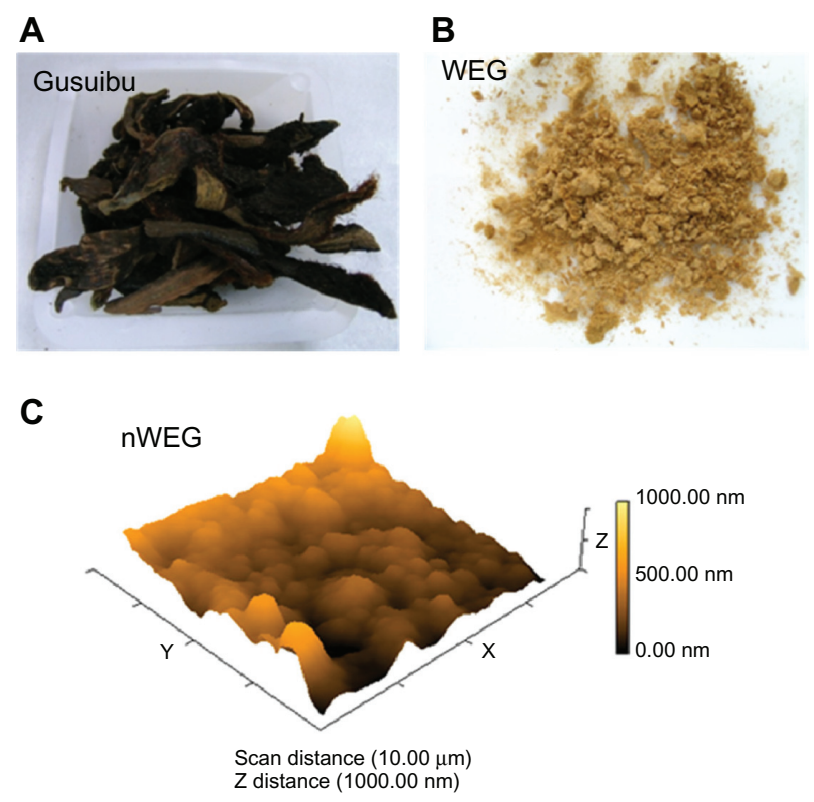

Figure I Preparation of the water extract of Gusuibu (WEG) and nanoparticles of the WEG (nWEG). Dry pieces of Gusuibu (A), Drynaria fortunei, were ground into a fine powder. WEG (B) and nWEG were prepared as described in Materials and Methods. The distribution of nWEG particles was analyzed using an atomic force microscope (C).

Buehler, Lake Bluff, IL) for 10 minutes in an aluminum oxide mortar. Fractions of particles were passed through a series of sieves. The mass percentage of each particle size range was detected. The distribution of particles of different sizes was observed and analyzed using an atomic force microscope (Mobile S, Nanosurf, Liestal District, Switzerland).

\section{Isolation of rat osteoblasts and drug treatment}

Rat osteoblasts were prepared from 3-day-old Wistar rat calvarias according to a previously described method. ${ }^{21}$ All procedures were performed according to the National Institutes of Health Guidelines for the Use of Laboratory Animals and approved by the Institutional Animal Care and Use Committee of Taipei Medical University (Taipei, Taiwan). Rat osteoblasts were seeded in Dulbecco's modified Eagle's medium (DMEM; Gibco-BRL, Grand Island, NY) supplemented with $10 \%$ heat-inactivated fetal bovine serum, L-glutamine, penicillin (100 IU/mL), and streptomycin $(100 \mu \mathrm{g} / \mathrm{mL})$ in $75-\mathrm{cm}^{2}$ flasks at $37^{\circ} \mathrm{C}$ in a humidified atmosphere of $5 \% \mathrm{CO}_{2}$. These bone cells were grown to confluence prior to drug treatment. Only the first passage of rat osteoblasts was used in this study. WEG and nWEG were dissolved in deionized distilled water and filtrated through $0.25-\mathrm{mm}$ filters. Rat osteoblasts were treated with different concentrations of WEG and nWEG for various time 
intervals in independent experiments. In protection assays, rat osteoblasts were exposed to $100 \mu \mathrm{M}$ hydrogen peroxide, $10 \mu \mathrm{g} / \mathrm{mL}$ WEG, $10 \mu \mathrm{g} / \mathrm{mL} \mathrm{nWEG}$, and a combination of hydrogen peroxide with WEG or nWEG for 24 hours. Cell viability, DNA fragmentation, and cell apoptosis were quantified. Sodium nitroprusside was administered to rat osteoblasts, and cell viability was assayed.

\section{Toxicity assays}

Toxicities of WEG and nWEG were evaluated by observing cell morphologies using a light microscope and assaying cell viability by a colorimetric 3-(4,5-dimethylthiazol-2-yl)-2,5diphenyltetrazolium bromide (MTT) assay, as per a previously described method. ${ }^{13}$ After drug treatment, morphologies of osteoblasts were observed and photographed using a light microscope. Rat osteoblasts $\left(2 \times 10^{4}\right.$ cells per well $)$ were seeded in 96-well tissue culture plates overnight. After treatment with WEG and nWEG, rat osteoblasts were cultured with new medium containing $0.5 \mathrm{mg} / \mathrm{mL}$ MTT for a further 3 hours. The blue formazan products in osteoblasts were dissolved in dimethyl sulfoxide and spectrophotometrically measured at a wavelength of $550 \mathrm{~nm}$.

\section{Quantification of DNA fragmentation}

DNA fragmentation in rat osteoblasts was quantified by the cellular DNA fragmentation enzyme-linked immunosorbent assay kit (Boehringer Mannheim, Indianapolis, IN) as described previously. ${ }^{22}$ Briefly, rat osteoblasts $\left(2 \times 10^{5}\right.$ cells $)$ were subcultured in 24-well tissue culture plates and labeled with BrdU overnight. Cells were harvested and suspended in the culture medium. One hundred microliters of cell suspension was added to each well of 96-well tissue culture plates. Rat osteoblasts were cocultured with WEG or nWEG for another 8 hours at $37^{\circ} \mathrm{C}$ in a humidified atmosphere of $5 \% \mathrm{CO}_{2}$. Amounts of BrdU-labeled DNA in the cytoplasm were quantified using an Anthos 2010 microplate photometer (Anthos Labtec Instruments, Lagerhausstrasse, Wals/ Salzburg, Austria) at a wavelength of $450 \mathrm{~nm}$.

\section{Analysis of apoptotic cells}

Apoptotic cells were determined using propidium iodide to detect DNA fragments in nuclei, according to a previously described method. ${ }^{23}$ After drug treatment, medium containing floating cells was collected, and attached cells were washed and trypsinized. Floating and trypsinized osteoblasts were collected in the same centrifuge tubes. After centrifugation and washing, cell pellets were fixed in cold $80 \%$ ethanol. Fixed cells were stained with propidium iodide. Apoptotic cells were quantified by detecting the proportion of rat osteoblasts arrested at the sub-G1 phase using flow cytometry (FACS Calibur, Becton Dickinson, San Jose, CA).

\section{Assays of osteoblast mineralization}

Osteoblast maturation was determined by evaluating cell mineralization using the von Kossa and Alizarin red $\mathrm{S}$ dye-staining protocols. ${ }^{24,25}$ Rat osteoblasts were treated with $10 \mu \mathrm{g} / \mathrm{mL}$ of WEG, $\mathrm{nWEG}$, or a combination of $10 \mathrm{nM}$ dexamethasone, $100 \mu \mathrm{g} / \mathrm{mL}$ ascorbic acid, and $10 \mathrm{mM}$ $\beta$-glycerophosphate for 21 days. After drug treatment, rat osteoblasts were washed with ice-cold phosphate-based saline buffer (0.14 M NaCl, $2.6 \mathrm{mM} \mathrm{KCl,} 8 \mathrm{mM} \mathrm{Na}_{2} \mathrm{HPO}_{4}$, and $1.5 \mathrm{mM} \mathrm{KH}_{2} \mathrm{PO}_{4}$ ) and then fixed in ice-cold $10 \%$ formalin for 20 minutes. For the von Kossa protocol, mineralized matrix was detected by treating fixed cells with $5 \%$ silver nitrate for 30 minutes, followed by subsequent washes with $5 \%$ sodium carbonate in 10\% formalin for 1 minute and 5\% sodium thiosulfate for 5 minutes. The reaction was stopped by washing cells twice with deionized water. For the Alizarin red S dye staining protocol, fixed osteoblasts were thoroughly rinsed and then incubated in $1 \%$ alcian blue $(\mathrm{pH} 2.5$; Fisher Scientific, Pittsburgh, PA) for 12 hours. Sections were then incubated in Alizarin red S (Fisher Scientific) for 8 minutes, dehydrated briefly in xylene and covered with a coverslip in Permount (Fisher Scientific). Mineralized nodules were visualized and counted under an inverted microscope. Each experiment was performed in duplicate wells and repeated 3 times.

\section{Statistical analyses}

The statistical significance of differences between the control and drug-treated groups was evaluated using Student's $t$-test, and differences were considered statistically significant at $P$ values of $<0.05$. Differences between drug-treated groups were considered significant when the $P$ value of Duncan's multiple-range test was $<0.05$. Statistical analysis between groups over time was carried out by a 2-way analysis of variance (ANOVA).

\section{Results Preparation of WEG and nWEG}

Dry pieces of Gusuibu (D. fortunei) (Figure 1A) were ground into a fine powder, and the WEG was prepared (Figure 1B). nWEG was prepared, and the distribution of the particles with different sizes was analyzed 
(Figure 1C). Results revealed that $>90 \%$ of $n W E G$ particles were $<1000 \mathrm{~nm}$.

\section{Toxicity of nWEG to rat osteoblasts}

Cell morphologies, cell viability, and apoptotic cells were analyzed to determine the cytotoxicity of nWEG to rat osteoblasts. Treatment of rat osteoblasts with 1, 10, 100, and $1000 \mu \mathrm{g} / \mathrm{mL}$ nWEG for 72 hours did not affect cell morphologies (data not shown). The results of the viability analyses also showed that exposure to $1,10,100$, and $1000 \mu \mathrm{g} / \mathrm{mL} \mathrm{nWEG}$ for 72 hours did not cause the death of rat osteoblasts (Figure 2A). Furthermore, after treatment for 72 hours, nWEG at 1, 10, 100, and $1000 \mu \mathrm{g} / \mathrm{mL}$ nWEG did not induce osteoblast apoptosis (Figure 2B).
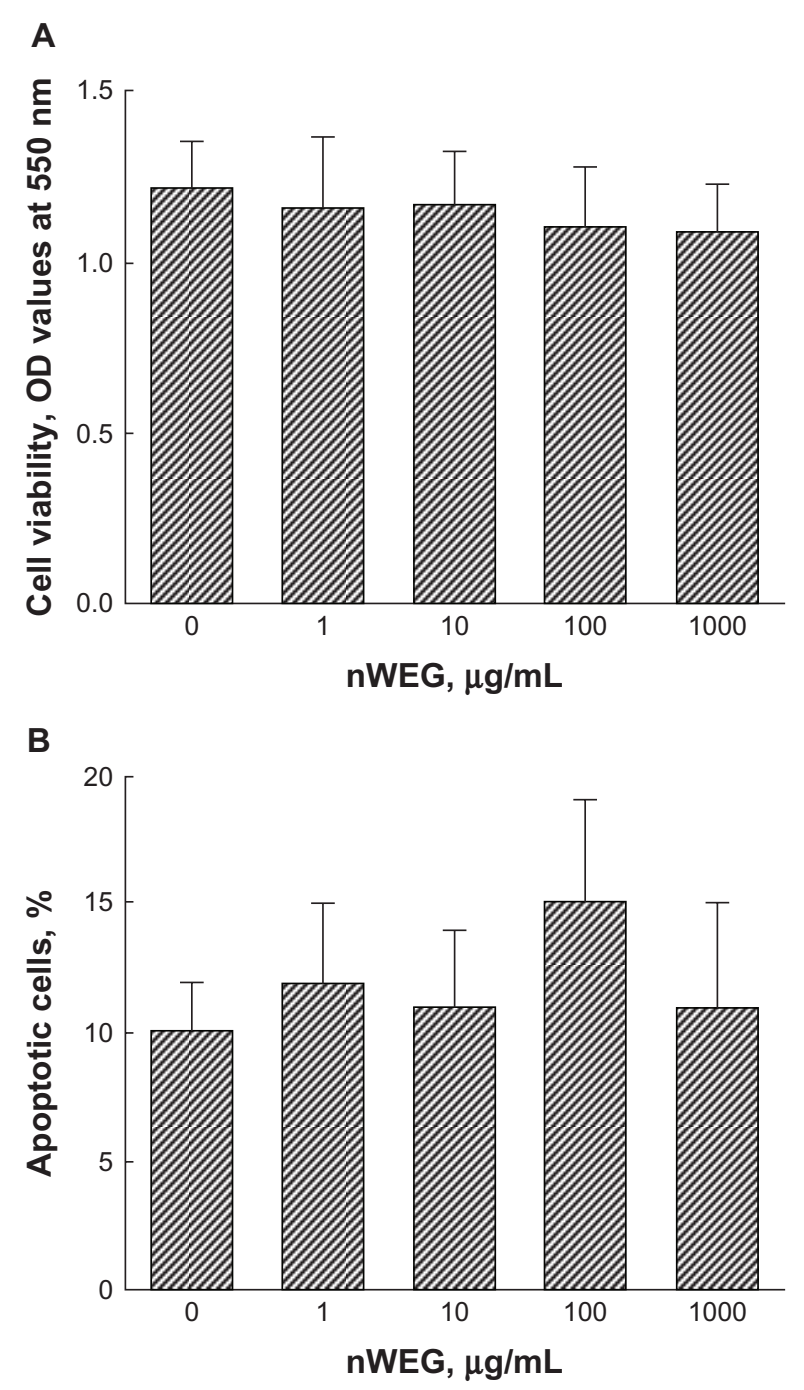

Figure 2 Effects of nanoparticles prepared from the water extract of Gusuibu (nWEG) on cell viability and apoptotic cells. Primary rat osteoblasts isolated from neonatal calvarias were exposed to I, 10, 100, and $1000 \mu \mathrm{g} / \mathrm{mL}$ of $\mathrm{nWEG}$ for 72 hours. The viability of rat osteoblasts was assayed using a colorimetric method (A). Cell apoptosis was quantified by flow cytometry (B).

Note: Each value represents the mean \pm SEM for $n=6$.
nWEG is safer to primary rat osteoblasts than WEG

Cell viability was analyzed carried out to compare the toxicities of WEG and nWEG to primary rat osteoblasts (Figure 3). Exposure of rat osteoblasts to $1000 \mu \mathrm{g} / \mathrm{mL}$ WEG for 24 and 48 hours did not influence cell viability (Figure 3A). Meanwhile, when the treatment time intervals reached 72 hours, WEG caused a significant $31 \%$ decrease in osteoblast viability. In comparison, exposure to $1000 \mu \mathrm{g} / \mathrm{mL}$ nWEG for 24,48 , and 72 hours did not affect the viability of rat osteoblasts (Figure 3B).

DNA fragmentation and apoptotic cells were analyzed to evaluate the mechanism of WEG-induced death of rat osteoblasts (Figure 4). Treatment of rat osteoblasts with $1000 \mu \mathrm{g} / \mathrm{mL}$ WEG for 72 hours induced DNA fragmentation by 2.4 -fold (Figure 4A). Following exposure to $1000 \mu \mathrm{g} / \mathrm{mL}$ nWEG for 72 hours, the genomic DNA of rat osteoblasts was not damaged. Treatment with $1000 \mu \mathrm{g} / \mathrm{mL}$ WEG for 72 hours induced apoptosis of rat osteoblasts by $20 \%$ (Figure 4B, C). nWEG did not cause osteoblast apoptosis. Sodium nitroprusside was administered to rat osteoblasts as a positive control (Figure 4). Exposure of rat osteoblasts to sodium nitroprusside caused significant 9.1-fold and $89 \%$ increases in DNA fragmentation and cell apoptosis, respectively (Figure 4A-C).

\section{nWEG has better cytoprotection against hydrogen peroxide-induced insults}

The effects of WEG and nWEG on stress-induced insults to primary rat osteoblasts were determined (Figure 5). Exposure of rat osteoblasts to $100 \mu \mathrm{M}$ hydrogen peroxide for 24 hours caused a significant $40 \%$ reduction in cell viability (Figure 5A). After treatment with $10 \mu \mathrm{g} / \mathrm{mL}$ WEG or nWEG alone, viability of rat osteoblasts did not change. Exposure to WEG decreased hydrogen-caused death of rat osteoblasts by $49 \%$. However, nWEG completely alleviated the hydrogen peroxide-caused decrease in cell viability (Figure 5A). Treatment of rat osteoblasts with $100 \mu \mathrm{M}$ hydrogen peroxide for 24 hours induced DNA fragmentation and cell apoptosis by 4.7 -fold and $54 \%$, respectively (Figure 5B, C). Neither WEG nor nWEG caused genomic DNA injury or cell apoptosis. Treatment of rat osteoblasts with WEG caused significant $57 \%$ and $45 \%$ decreases in hydrogen peroxide-induced DNA fragmentation and cell apoptosis, respectively (Figure 5B, C). In comparison, nWEG completely lowered hydrogen peroxide-induced DNA damage and caused a $65 \%$ attenuation of oxidative stress-triggered apoptosis (Figure 5B, C). 
A

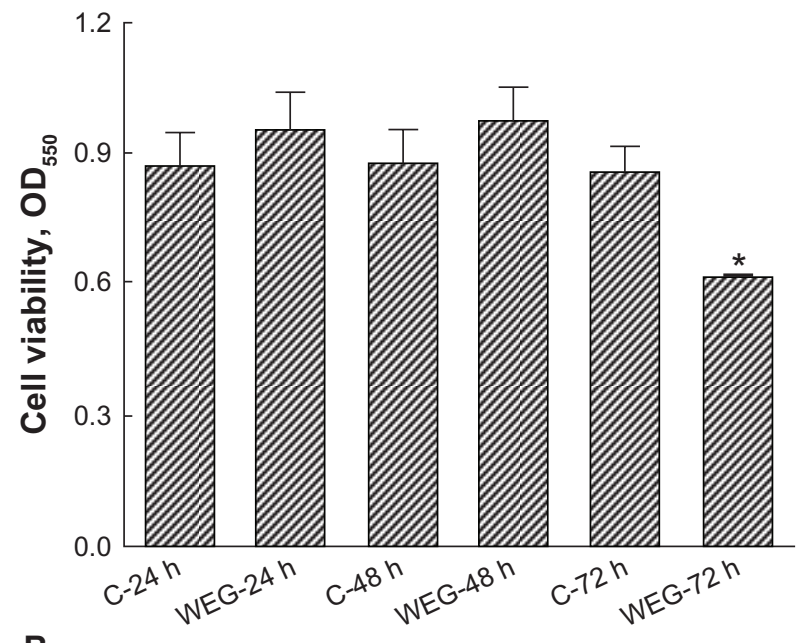

B

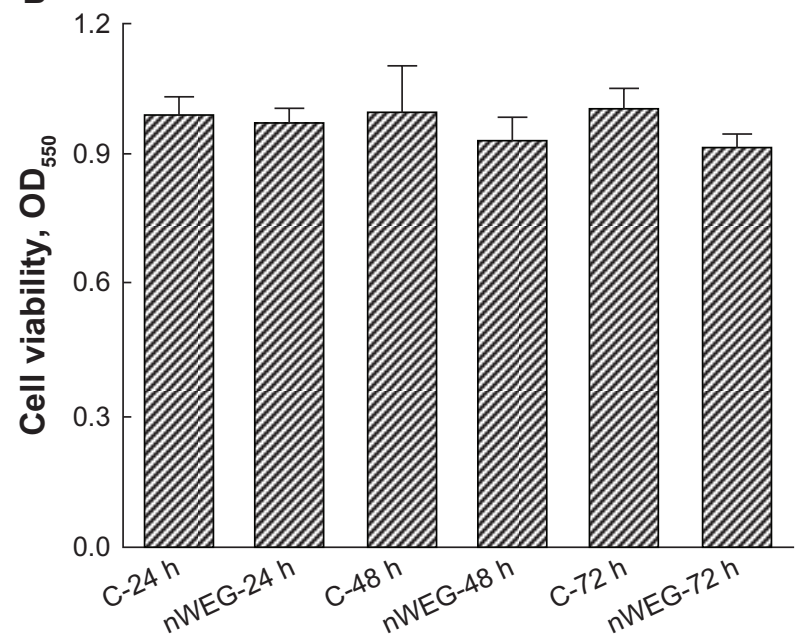

Figure 3 Effects of the water extract of Gusuibu (WEG) and nanoproducts of the WEG ( $n W E G$ ) on cell viability. Primary rat osteoblasts isolated from neonatal calvarias were exposed to $1000 \mu \mathrm{g} / \mathrm{mL}$ of WEG (A) and nWEG (B) for 24,48 , and 72 hours. Cell viability was assayed according to a colorimetric method.

Notes: Each value represents the mean \pm SEM for $n=6$. *Indicates that a value significantly differs from the respective control, $P<0.05$.

The defense by WEG and nWEG against nitrosative stress-induced insults to rat osteoblasts was further evaluated (Figure 5D). Exposure of rat osteoblasts to $2 \mathrm{mM}$ sodium nitroprusside for 24 hours caused a $78 \%$ reduction in cell viability. Treatment with WEG or nWEG alone at $10 \mu \mathrm{g} / \mathrm{mL}$ did not influence the viability of rat osteoblasts. However, exposure to WEG and $\mathrm{nWEG}$ significantly attenuated sodium nitroprusside-induced death of rat osteoblasts by $36 \%$ and $56 \%$, respectively (Figure 5D).

\section{nWEG promotes osteoblast mineralization}

Effects of WEG and nWEG on osteoblast maturation were determined by analyzing cell mineralization (Figure 6).
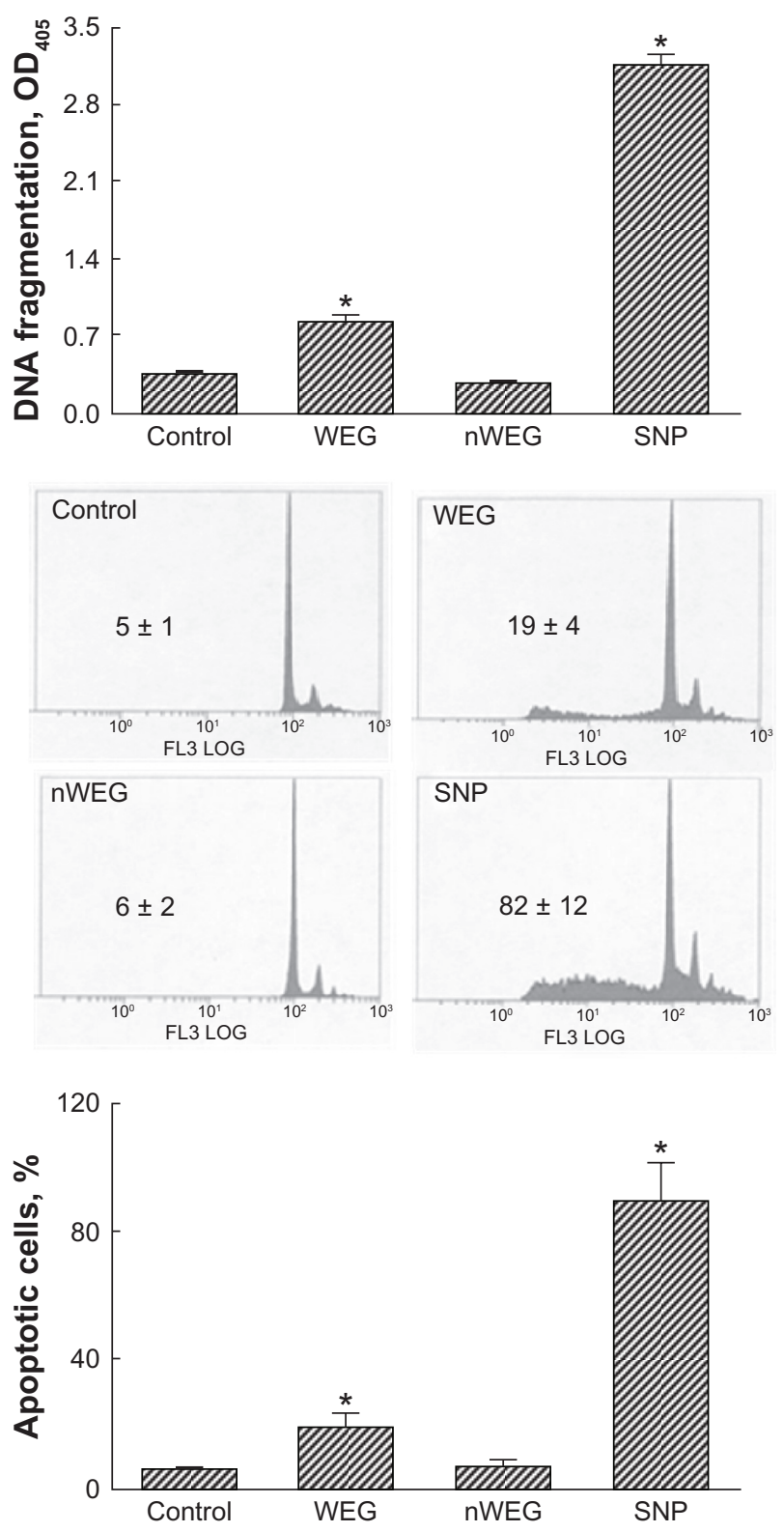

Figure 4 Effects of the water extract of Gusuibu (WEG) and nanoproducts of the WEG (nWEG) on DNA fragmentation and cell apoptosis. Primary rat osteoblasts isolated from neonatal calvarias were exposed to $1000 \mu \mathrm{g} / \mathrm{mL}$ of WEG and $\mathrm{nWEG}$ for 72 hours. DNA fragmentation was assayed using an enzyme-linked immunosorbent assay kit (A). Cell apoptosis was analyzed and quantified by flow cytometry (B, C). Sodium nitroprusside (SNP) was administered to rat osteoblasts as a positive control.

Notes: Each value represents the mean \pm SEM for $n=6$. "Indicate that a value significantly $(P<0.05)$ differs from control and WEG-treated groups, respectively.

Results of von Kossa staining revealed that no mineralized nodules were observed in control osteoblasts (Figure 6A, left-top panel). After repeated treatment of primary rat osteoblasts with $10 \mu \mathrm{g} / \mathrm{mL}$ WEG for 21 days, mineralized nodules were observed (right-top panel). Exposure of rat osteoblasts to nWEG at the same concentration of $10 \mu \mathrm{g} / \mathrm{mL}$ for 21 days stimulated more mineralized nodules (left-bottom panel). Analysis with the Alizarin red S dye-staining protocol 
A

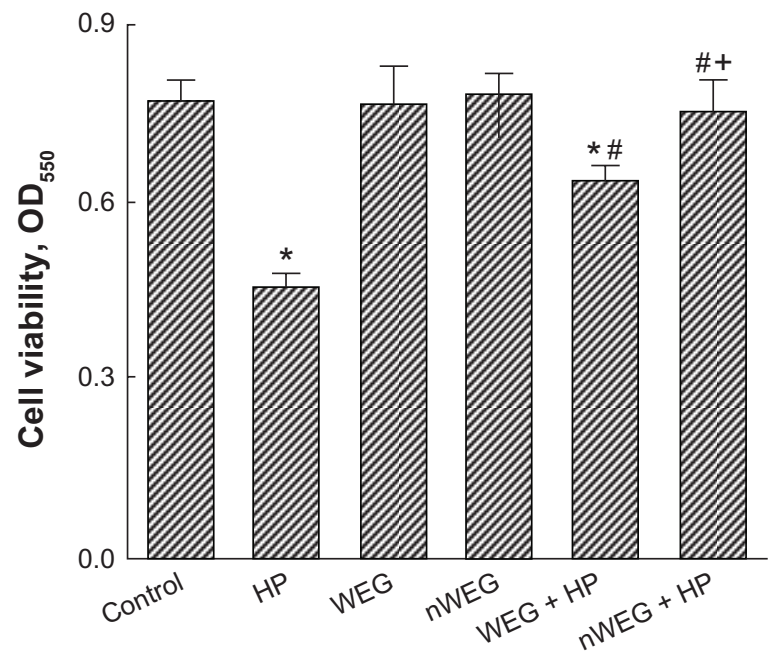

C

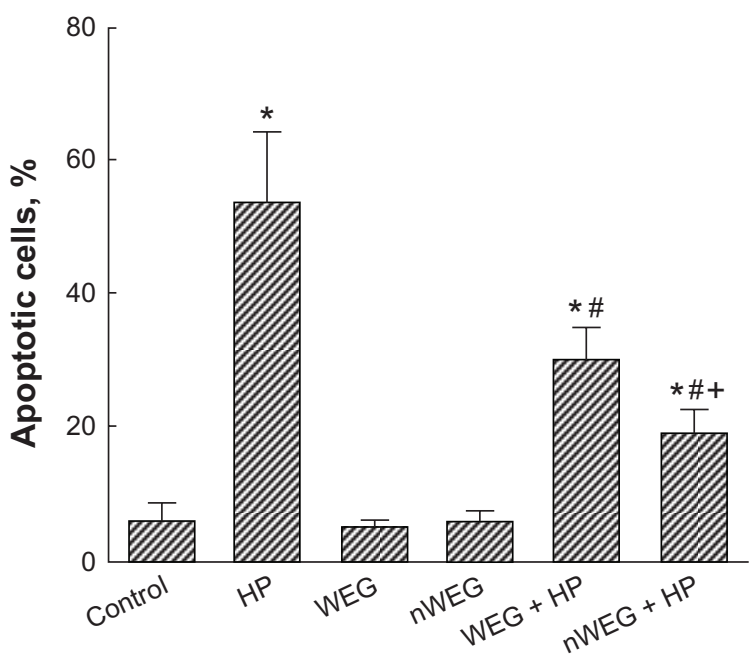

B

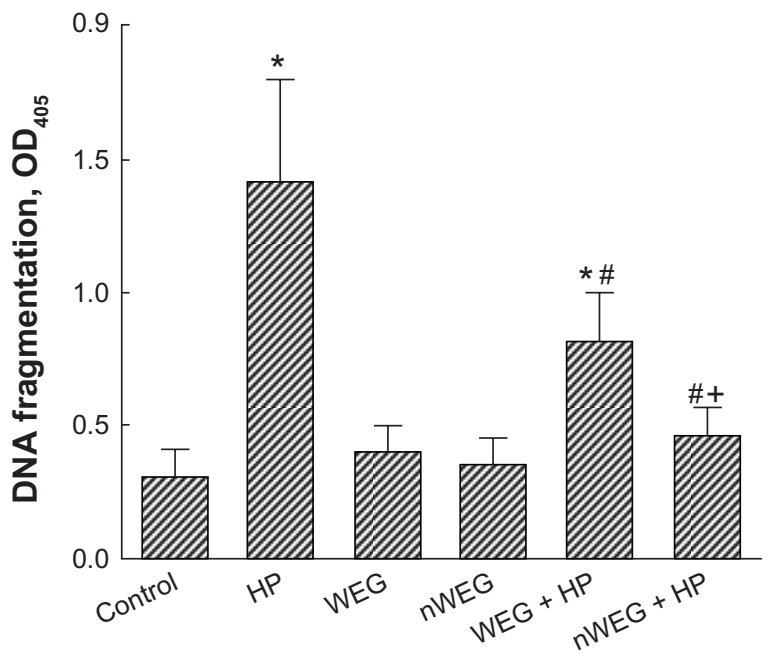

D

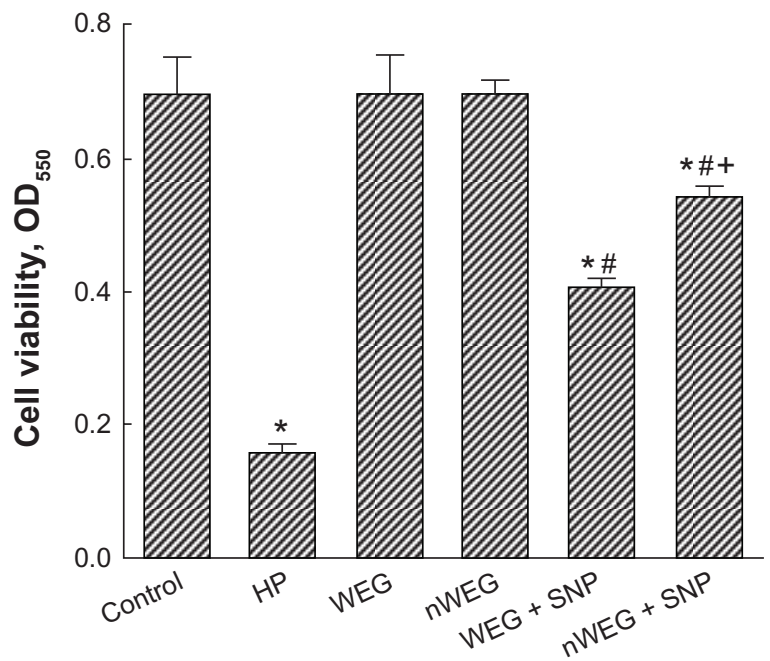

Figure 5 Effects of the water extract of Gusuibu (WEG) and nanoproducts of the WEG (nWEG) on hydrogen peroxide- (HP) and sodium nitroprusside (SNP)-induced cell insults. Primary rat osteoblasts isolated from neonatal calvarias were exposed to $100 \mu \mathrm{M} \mathrm{HP}, 10 \mu \mathrm{g} / \mathrm{mL}$ WEG, $10 \mu \mathrm{g} / \mathrm{mL} \mathrm{nWEG}$, and a combination of HP with WEG or nWEG for 24 hours. Cell viability (A), DNA fragmentation (B), and cell apoptosis (C) were quantified. SNP was administered to rat osteoblasts, and cell viability was assayed (D).

Note: Each value represents the mean \pm SEM for $n=6$. $^{*, *+}$ Indicate that a value significantly $(P<0.05)$ differs from control, and HP- and WEG-treated groups, respectively.

showed similar results as with the von Kossa method; that is, nWEG had better potential to promote osteoblast mineralization than WEG (Figure 6B, right-top and left-bottom panels). A combination of dexamethasone, ascorbic acid, and $\beta$-glycerophosphate was applied to rat osteoblasts as a positive control, and the results revealed such treatment massively stimulated osteoblast maturation (Figure 6A, 6B, right-bottom panels).

\section{Discussion}

Nanoparticles prepared from a Gusuibu water extract can promote osteoblast maturation and do not cause cytotoxicity to primary rat osteoblasts. In this study, we showed that treatment of rat osteoblasts with $1,10,100$, and $1000 \mu \mathrm{g} / \mathrm{mL}$ nWEG for 24,48 , or 72 hours did not change cell morphologies or cell viability. Analysis of the cell cycle further showed that the nanosized Gusuibu did not induce osteoblast apoptosis. Thus, our present results show that Gusuibu nanoproducts even at a high concentration of $1000 \mu \mathrm{g} / \mathrm{mL}$ were safe to rat osteoblasts. In parallel, when primary rat osteoblasts were repeatedly treated with $10 \mu \mathrm{g} / \mathrm{mL}$ nanoparticles of Gusuibu water extracts for 21 days, cell maturation was significantly promoted. Liu et al used nanotechnology to prepare Danshen (S. miltiorrhiza) products and found that these nanoproducts possessed stronger antioxidant bioactivitives than the traditional ground particles. ${ }^{5}$ In addition, nano-Ganoderma spores 

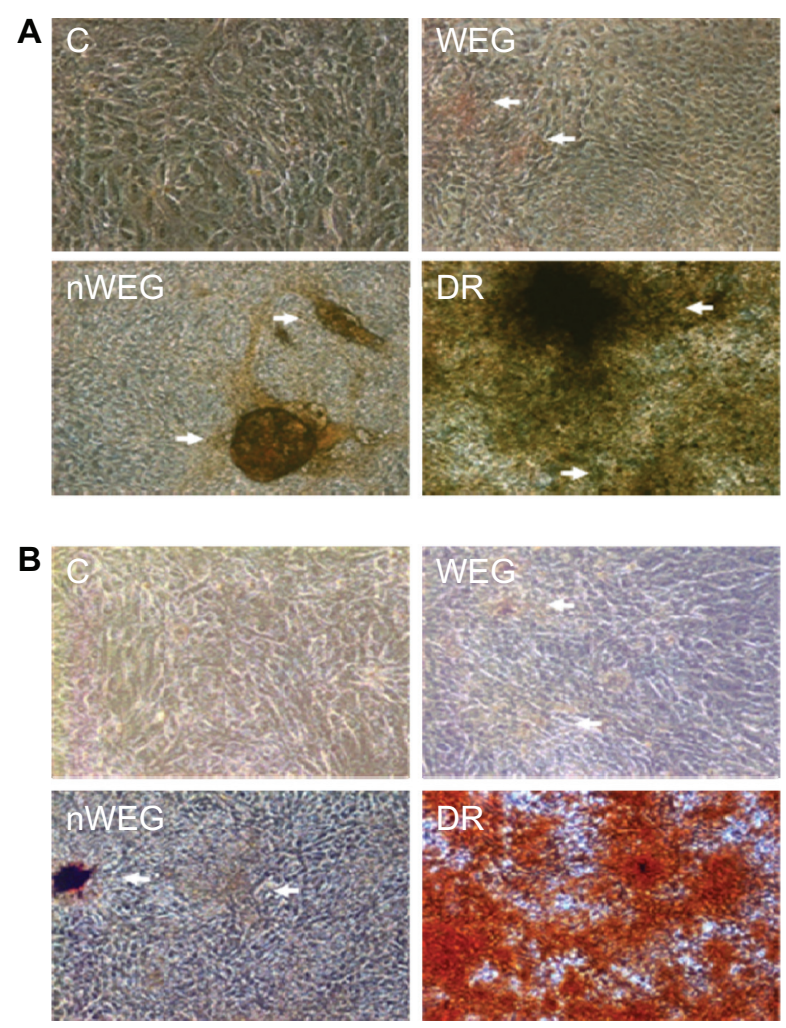

Figure 6 Effects of the water extract of Gusuibu (WEG) and nanoproducts of the WEG (nWEG) on osteoblast maturation. Primary rat osteoblasts isolated from neonata calvarias were exposed to $10 \mu \mathrm{g} / \mathrm{mL}$ WEG, $10 \mu \mathrm{g} / \mathrm{mL} \mathrm{nWEG}$, or a differentiation agent, including dexamethasone, ascorbic acid, and $\beta$-glycerophosphate, for $2 \mathrm{I}$ days. Mineralized nodules were stained using the von Kossa $(\mathbf{A})$ and Alizarin red S-staining protocols (B), and then photographed with a light microscope. 100x.

are more easily taken up and have better antitumor activity. ${ }^{6}$ During bone healing, osteoblast maturation plays a key role in the process of bone formation. ${ }^{26}$ Hence, the nanoparticles prepared from Gusuibu extracts could be better updated by rat osteoblasts than normal-sized WEG and may promote more bone formation by stimulating cell maturation.

Nanoparticles prepared from Gusuibu extracts were much safer to primary rat osteoblasts than was normal-sized WEG. The present results show that exposure of rat osteoblasts to $1000 \mu \mathrm{g} / \mathrm{mL}$ nWEG for 72 hours did not cause cell death. By comparison, treatment with $1000 \mu \mathrm{g} / \mathrm{mL}$ WEG for 72 hours decreased cell viability. Thus, this study shows that WEG induced greater cytotoxic to rat osteoblasts than nWEG. WEG induced DNA fragmentation and sub-G1 arrest of rat osteoblasts. DNA fragmentation and arrest at the sub-G1 phase are two typical characteristics of cells undergoing apoptosis. ${ }^{10,27}$ Hence, WEG at a high concentration caused the death of rat osteoblasts via an apoptotic mechanism. Nanoparticles were proposed as a good delivery system for low-molecular-weight heparin due to their low toxicity. ${ }^{28} \mathrm{Li}$ et al also reported that nanostructured hydroxyapatite pellets can enhance cell attachment and promote proliferation of osteoblast cells. ${ }^{29}$ This study further showed that nanoparticles of Gusuibu extracts have lower cytotoxicity to primary rat osteoblasts.

Nanoparticles of Gusuibu water extracts can lessen hydrogen peroxide- and sodium nitroprusside-induced insults to primary rat osteoblasts. This study showed that hydrogen peroxide decreased cell viability and induced DNA fragmentation and cell cycle arrest. Sodium nitroprusside reduces the viability of rat osteoblasts. Exposure to hydrogen peroxide and sodium nitroprusside elevates cellular oxidative and nitrosative stress. ${ }^{13}$ Thus, when rat osteoblasts were exposed to hydrogen peroxide and sodium nitroprusside, the augmented oxidative and nitrosative stress caused cell death through an apoptotic pathway. At the same time, after treatment with the nanoproducts of Gusuibu extracts, the hydrogen peroxide-induced apoptotic insult to rat osteoblasts was significantly alleviated. Wang et al reported that 11 flavonoids are found in the extracts of Gusuibu, which have osteoprotective effects. ${ }^{17}$ Our previous study also demonstrated that naringin, a flavonoid, may be one of the bioactive components in Gusuibu water extracts. ${ }^{15}$ Therefore, the flavonoid components in nanoparticles of Gusuibu extracts may contribute to the osteoprotection against oxidative or nitrosative stress-induced apoptosis of rat osteoblasts.

Gusuibu nanoproducts have better antioxidant activity than normal-sized particles. This study showed that both of nWEG and WEG could decrease hydrogen peroxideinduced death, DNA fragmentation, and apoptosis. By comparison, the nanoparticles of the Gusuibu water extract significantly caused much greater alleviation of oxidative and nitrosative stress-induced insults to rat osteoblasts than did normal-sized products. In human intestinal Caco-2 cells, nanoparticles of apoferritin-encapsulated platinum were shown to possess better catalytic efficiency and long-term stability, and reduced hydrogen peroxide-induced oxidative injury. ${ }^{30}$ In addition, nanoparticles prepared from Danshen showed stronger antioxidant bioactivitives. ${ }^{5}$ During bone fracture-induced inflammation, enhanced oxidative stress can decrease osteoblast differentiation and bone formation. ${ }^{31}$ Our previous study also showed that sodium nitroprussidecaused nitrosative stress induced apoptosis of osteoblasts, but the water extract of Gusuibu attenuated such damage. ${ }^{15,16}$ Consequently, our previous and present studies demonstrate that Gusuibu has the potential to promote bone healing by attenuating nitrosative and oxidative stress-induced apoptotic insults to osteoblasts. In particular, nanoproducts 
of Gusuibu water extracts have much better osteoprotective effects.

Nanoparticles prepared from Gusuibu water extracts can stimulate osteoblast maturation. The present results analyzed by the von Kosa and Alizarin red staining protocols revealed that Gusuibu nanoproducts promoted osteoblast mineralization. The succession of osteoblast development includes osteoprogenitor proliferation, matrix maturation, and cell mineralization. ${ }^{26}$ There are varieties of differentiation-related proteins, such as insulin-like growth factor-1, bone morphogenetic proteins, alkaline phosphatase, osteopontin, and osteocalcin, which are involved in regulating osteogenic differentiation. ${ }^{32-34}$ Our previous study reported that Gusuibu water extracts can promote osteoblast maturation by regulating these bone differentiation-related gene expressions..$^{15}$ As a result, one of the major reasons explaining Gusuibu nanoproducts' promotion of osteoblast maturation is the effects of these nanoparticles on regulating these osteogenesis-related gene expressions. By comparison with normal-sized products, nanoparticles of Gusuibu extracts had improved osteogenic mineralization. De Oliveira and Nanci reported that the nanotexturing of titanium-based surfaces upregulated the early expression of bone sialoprotein and osteopontin in osteogenic cell cultures. ${ }^{34}$ By changing the resonance, the localized nanoparticle surface plasmon is conducive to optically detect biomolecular interactions. ${ }^{4}$ Thus, nanotechnology can be applied to the nanopreparation of traditional Chinese medicines in order to enhance bone formation by stimulating osteoblast maturation.

\section{Conclusion}

In conclusion, this study shows that nanoparticles prepared from the Gusuibu water extract did not induce DNA fragmentation or apoptotic death of primary rat osteoblasts. By comparison, products of Gusuibu extracts of normal sizes at a high concentration caused the death of rat osteoblasts via an apoptotic mechanism. Both nano- and normalsized particles of Gusuibu water extracts could lessen hydrogen peroxide- and sodium nitroprusside-induced DNA fragmentation and apoptosis of rat osteoblasts. Meanwhile, the nanoproducts had stronger antioxidant activities of scavenging oxidative and nitrosative stress. As with normalsized products, nanoparticles of Gusuibu water extracts could also promote osteoblast mineralization. However, Gusuibu nanoproducts stimulated greater osteoblast maturation than products of normal sizes. Therefore, our present results suggest that nanoparticles prepared from the water extract of Gusuibu have stronger osteoprotection against stress-induced apoptotic insults to primary rat osteoblasts and possess better promotion of bone cell maturation. The pharmacokinetics and pharmcodynamics of nanoproducts of Gusuibu water extract will be further evaluated in our future study.

\section{Acknowledgments}

This study was supported by the National Taipei University of Technology-Taipei Medical University Joint Research Program (NTUT-TMU-98-08; NTUT-TMU-100-06) and Wan Fang Medical Center (100 swf08), Taipei, Taiwan.

\section{Disclosure}

The authors report no conflicts of interest in this work.

\section{References}

1. Farokhzad OC, Langer R. impact of nanotechnology on drug delivery. ACS Nanol. 2009;3:16-20.

2. Chen Q, Li DY, Oiwa K. The coordination of protein motors and the kinetic behavior of microtubule - a computational study. Biophys Chem. 2007;129:60-69.

3. Hsieh BY, Chang YF, Ng MY, et al. Localized surface plasmon coupled fluorescence fiber-optic biosensor with gold nanoparticles. Anal Chem. 2007;79:3487-3493.

4. Faunce TA, White J, Matthaei KI. Integrated research into the nanoparticle-protein corona: a new focus for safe, sustainable and equitable development of nanomedicines. Nanomedicine. 2008;3: 859-866.

5. Liu JR, Chen GF, Shih HN, Kuo PC. Enhanced antioxidant bioactivity of Salvia miltiorrhiza (Danshen) products prepared using nanotechnology. Phytomedicine. 2008;15:23-30.

6. Liu X, Wang JH, Yuan JP. Pharmacological and anti-tumor activities of Ganoderma spores processed by top-down approaches. J Nanosci Nanotechnol. 2005;5:2001-2013.

7. Seeman E, Delmas PD. Bone quality - the material and structural basis of bone strength and fragility. N Engl J Med. 2006;354:2250-2261.

8. Yeler H, Tahtabas F, Candan F. Investigation of oxidative stress during fracture healing in the rats. Cell Biochem Funct. 2005;23:137-139.

9. Shapiro F. Bone development and its relation to fracture repair. The role of mesenchymal osteoblasts and surface osteoblasts. Eur Cells Mater. 2008; 15:53-76.

10. Chen RM, Chen TL, Chiu WT, Chang CC. Molecular mechanism of nitric oxide-induced osteoblast apoptosis. J Orthop Res. 2005;23: 462-468.

11. Chang CC, Liao YS, Lin YL, Chen RM. Nitric oxide protects osteoblasts from oxidative stress-induced apoptotic insults via a mitochondriadependent mechanism. J Orthop Res. 2006;24:1917-1925.

12. Tai YT, Cherng YG, Chang CC, Hwang YP, Chen JT, Chen RM. Pretreatment with low nitric oxide protects osteoblasts from high nitric oxide-induced apoptotic insults through regulation of c-Jun $\mathrm{N}$-terminal kinase/c-Jun-mediated $\mathrm{Bcl}-2$ gene expression and protein translocation. J Orthop Res. 2007;25:625-635.

13. Ho WP, Chan WP, Hsieh MS, Chen RM. Runx2-mediated Bcl-2 gene expression contributes to nitric oxide protection against oxidative stressinduced osteoblast apoptosis. J Cell Biochem. 2009;108:1084-1093.

14. Chen RM, Lin YL, Chou CW. GATA-3 transduces survival signals in osteoblasts through upregulation of $b c l-x_{L}$ gene expression. J Bone Miner Res. 2010;25:2193-2204.

15. Huang TY, Chen TL, Liao MH, et al. Drynaria fortunei J. Sm. promotes osteoblast maturation by inducing differentiation-related gene expression and protecting against oxidative stress-induced apoptotic insults. J Ethnopharmacol. 2010;131:70-77. 
16. Liu HC, Chen RM, Jian WC, Lin YL. Cytotoxic and antioxidant effects of the water extract of traditional Chinese herb Gusuibu (Drynaria fortunei) on rat osteoblasts. J Formos Med Assoc. 2001;100: 383-388.

17. Wang XL, Wang NL, Zhang Y, et al. Effects of eleven flavonoids from the osteoprotective fraction of Drynaria fortunei (KUNZE) J. Sm. on osteoblastic proliferation using an osteoblast-like cell line. Chem Pharm Bull. 2008;56:6-51.

18. Long M, Qiu D, Li F, Johnson F, Luft B. Flavonoid of Drynaria fortunei protects against acute renal failure. Phytother Res. 2005;19:422-427.

19. Wong RW, Rabie AB. Systemic effect of crude extract from rhizome of Drynaria fortunei on bone formation in mice. Phytother Res. 2006;20: 313-315.

20. Ou KL, Wu J, Lai WF, et al. Effects of the nanostructure and nanoporosity on bioactive nanohydroxyapatite/reconstituted collagen by electrodeposition. J Biomed Mater Res. 2010;92:906-912.

21. Chen RM, Lin YL, Jean WC, Chen JS, Wang JH, Liu HC. Nitric oxide induces osteoblast apoptosis through the de novo synthesis of Bax protein. J Orthop Res. 2002;20:295-302.

22. Chang HC, Chen TG, Tai YT, Chen TL, Chiu WT, Chen RM. Resveratrol attenuates oxidized LDL-evoked Lox-1 signaling and consequently protects against apoptotic insults to cerebrovascular endothelial cells. J Cerebr Blood Flow Met. 2011;31:842-854.

23. Lin YL, Chang HC, Chen TL, et al. Resveratrol protects against oxidized LDL-induced breakage of the blood-brain barrier by lessening disruption of tight junctions and apoptotic insults to mouse cerebrovascular endothelial cells. J Nutr. 2010;140:2187-2192.

24. Cooper LF, Yliheikkila PK, Felton DA, Whitson SW. Spatiotemporal assessment of fetal bovine osteoblast culture differentiation indicates a role for BSP in promoting differentiation. J Bone Min Res. 1998;13: 620-632.
25. Reseland JE, Syversen U, Bakke I, et al. Leptin is expressed in and secreted from primary cultures of human osteoblasts and promotes bone mineralization. J Bone Miner Res. 2001;16:1426-1433.

26. Aubin JE. Bone stem cells. J Cell Biochem. 1998;30-31:73-82.

27. Lee ST, Wu TT, Yu PY, Chen RM. Apoptotic insults to human HepG2 cells induced by S-(+)-ketamine occurs through activation of a Bax-mitochondria-caspase protease pathway. Brit J Anaesth. 2009;102:80-89.

28. Eidi H, Joubert O, Attik G, et al. Cytotoxicity assessment of heparin nanoparticles in NR8383 macrophages. Int J Pharm. 2010;396:156-165.

29. Li H, Khor KA, Chow V, Cheang P. Nanostructural characteristics, mechanical properties, and osteoblast response of spark plasma sintered hydroxyapatite. J Biomed Mater Res. 2007;82:296-303.

30. Zhang L, Laug L, Münchgesang W, et al. Reducing stress on cells with apoferritin-encapsulated platinum nanoparticles. Nano Lett. 2010; 10:219-223.

31. Shouhed D, Kha HT, Richardson JA, Amantea CM, Hahn TJ, Parhami F. Osteogenic oxysterols inhibit the adverse effects of oxidative stress on osteogenic differentiation of marrow stromal cells. J Cell Biochem. 2005;95:1276-1283.

32. Van Leeuwen JP, van Driel M, van den Bemd GJ, Pols HA. Vitamin D control of osteoblast function and bone extracellular matrix mineralization. Crit Rev Eukar Gene Exp. 2001;11:199-226.

33. Koch H, Jadlowiec JA, Campbell PG. Insulin-like growth factor-I induces early osteoblast gene expression in human mesenchymal stem cells. Stem Cells Dev. 2005;14:621-631.

34. De Oliveira PT, Nanci A. Nanotexturing of titanium-based surfaces upregulates expression of bone sialoprotein and osteopontin by cultured osteogenic cells. Biomaterials. 2004;25:403-413.
International Journal of Nanomedicine

\section{Publish your work in this journal}

The International Journal of Nanomedicine is an international, peerreviewed journal focusing on the application of nanotechnology in diagnostics, therapeutics, and drug delivery systems throughout the biomedical field. This journal is indexed on PubMed Central,

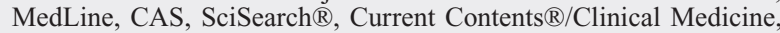

\section{Dovepress}

Journal Citation Reports/Science Edition, EMBase, Scopus and the Elsevier Bibliographic databases. The manuscript management system is completely online and includes a very quick and fair peer-review system, which is all easy to use. Visit http://www.dovepress.com/ testimonials.php to read real quotes from published authors. 